\title{
An Exploration of Dualisms in Female Perceptions of IT Work
}

\section{L. von Hellens, S. H. Nielsen, and J. Beekhuyzen Griffith University, Brisbane, Australia.}

\section{l.vonhellens@griffith.edu.au s.nielsen@griffith.edu.au j.beekhuyzen@griffith.edu.au}

\begin{abstract}
This paper explores the way that professional women working in the IT industry discuss the nature of their work. Previous work suggested that the way women talk about their work reinforces widely held impressions of the Information Technology industry (Nielsen, von Hellens, Beekhuyzen and Trauth 2003). In this paper Structuration Theory illuminates how this talk is characterised by dualisms which are not always consistent with the womens' lived experiences. The interview data reveals contradictions in these dualisms, indicating that these polarised views of women and IT work are being undermined by women in the IT industry. The perceptions of the interviewees are discussed as structures of signification that need to be altered in order to successfully challenge these dualisms. This paper suggests that mentoring, interactions with professional IT organisations, and professional IT women talking to females in their IT education years can give new ideas to the perceptions of IT and thus challenge these dualisms. It is suggested that exposing females in their IT education years to the professional IT women who are challenging these dualisms is an essential part of transforming these structures of signification. This research is part of an ongoing project (WinIT) commenced in 1995, which seeks to understand the declining female participation in IT education and work. In order to have a better understanding of the way women help configure the institutional realm of IT work, we propose that more qualitative studies of women at work in IT as well as women talking about IT are needed.
\end{abstract}

Keywords : Women in IT, Structuration Theory, Australia, Mentoring

\section{Introduction}

This paper examines the perceptions of women in the IT industry as expressed in their discourse about IT work. Giddens' structuration theory is used to illuminate how women construct and express their everyday experiences in this very competitive, declining female workforce. In particular, Giddens' notions of dualisms, routinisation and ontological security have provided a different perspective on women's perceptions of their work.

The research data was collected primarily through interviews with female IT Professionals, and a small number of male IT Professionals and is part of an ongoing project (WinIT) commenced in 1995, which

Material published as part of these proceedings, either on-line or in print, is copyrighted by Informing Science. Permission to make digital or paper copy of part or all of these works for personal or classroom use is granted without fee provided that the copies are not made or distributed for profit or commercial advantage AND that copies 1) bear this notice in full and 2) give the full citation on the first page. It is permissible to abstract these works so long as credit is given. To copy in all other cases or to republish or to post on a server or to redistribute to lists requires specific permission from the publisher at Publisher@InformingScience.org seeks to understand the declining female participation in IT education and work (von Hellens and Nielsen, 2001). Research work is continuing on the construction of female identities and the question of gender differences in IT work (Anthias, 1999; Nielsen, von Hellens and Beekhuyzen (forthcoming)). 
The declining participation of women in the IT industry is a complex issue and there is now a considerable body of research literature; for example, see the review by Ahuja (2002). There has been a small, though noticeable, rise in female participation in the traditionally male-dominated professions of science, engineering and medicine. However, there has not been a corresponding trend in the information technology sector. At the end of 1999 women represented just 29 percent of the workforce in the US technology sector, according to a study by the White House Council of Economic Advisers (2000). That is down from 40 percent of the workforce in 1986. By the start of the last decade, the proportion of females in the IT workforce was beginning to decline in most western countries (von Hellens, Pringle, Nielsen and Greenhill, 2000). This is despite the idea that "women may prove to be a key resource of skilled technology workers for International IT markets" (Maitland, 2001).

The WinIT research carried out to this point has sought to develop an understanding of complexity and social embededness of the problem of IT recruitment. Particularly, the research has focused on the cultural and gender factors affecting female recruitment (von Hellens and Nielsen, 2001). A conceptual model of the identified factors was developed and such an approach was found to be useful in examining the situation with relation to high school students and first year university students (Nielsen, vo n Hellens, Pringle and Greenhill, 1999). The research considers factors such as media representations of IT, peer, school and parental influences. Both male and female students lacked information about IT work and education and did not demonstrate any understanding about the nature of IT work. Overwhelmingly the students perceived IT as a ma sculinised domain and the female students mainly saw IT courses as boring and difficult.

Our more recent research has focused on women working in the IT industry and IT academia, where the significance of informed choice is more evident (Pringle, Nielsen, von Hellens, Greenhill and Parfitt, 2000; Trauth, Nielsen and von Hellens, 2000; von Hellens et al., 2000). These women have resisted in some way the influences which discourage young women from entering IT and have persisted in deve loping their IT careers. This paper presents early attempts to reexamine texts of professional women's interviews using some concepts from structuration theory. These concepts were initially established as relevant through a rereading of the interviews.

Until 1999, the first and second authors of this paper (the primary researchers of WinIT) had been primarily focusing the WinIT project on university and high school students. In 1999, the WinIT research was extended to cover female IT professionals and initial results were published (Pringle et al. 2000; von Hellens et al., 2000). In collaboration with Professor Eileen Trauth in 2000, the research focus further expanded to include more interviews with professional women in IT. Both parties carried out interviews with women from a variety of backgrounds.

In the last two decades structuration theory has been applied to information systems research in a number of ways (Walsham and Han, 1990; Jones, 1999; Walsham, 2002). This paper is in the growing tradition information systems research where "particular concepts from Giddens' writing are adopted" (Jones 1999). Most of these studies have focused on the nature of technology and its relationship to human agents in information systems development and use. We intend to extend this application to the problem of the relationships between the IT education and commercial industries, social perceptions of IT education and work and the human resource requirements of the IT industry. The usefulness of structuration theory has also been claimed in a number of other related fields, such as gender studies. Halford and Leonard (2001) suggest that Giddens offers "considerable promise for the development of fuller understandings between gender, power and organisation".

Theory of structuration is used in this paper as a basis for analysing the changing relationship between social structures (the IT education and commercial industries) on the one hand, and human agency (students and IT professionals) on the other hand. It is not our intention to describe Giddens' theory of structuration, or discuss its many critics. At this stage of the research we intend to apply some of the 
concepts of structuration to the interview data to seek further illumination of the complex topic of women in IT.

The research deals with two extremely complex areas; firstly the expressed attitudes and motivations of young people, particularly females, choosing educational and career paths and the social factors which influence them; secondly, the nature of an industry which is difficult to compare to any other - being of fairly recent origin, not governed by the same professional and regulatory constraints as other complex industries (such as engineering, accounting and law) and subject to recent upheavals in terms of skills demands and shortages.

There is a very large body of literature on the demand for IT skills, however our research differs from the primarily positivist approach taken in IT skills research. For example Todd, McKeen and Gallupe (1995) reported that according to their observations, the skills which are required from IT professionals are business, technical and systems skills. From a structuration theory point of view, demand for IT skills cannot be treated as a matter of social fact, but is implicated in the structuration of the IT industry, and reinforced or challenged by industry participants. In our research we are studying how women perceive and represent those skills in their discourse about their work. These perceptions and their representations may not have a straightforward relationship to the types of categorisations (business/technical, etc) made by studies of IT skills. In this paper we focus on routinisation and ontological security in the construction of this discourse. Our current research extends this work to investigate how women's perceptions, expressed in their discourse help construct female identities in the IT workforce (Nielsen et al., (forthcoming)).

The interview data is discussed throughout the paper using the concepts of duality and dualisms, routinisation and interpretive schemes and signification. The focus is on structures of signification since the research has so far collected only interview and survey data. To use the other dimensions of Giddens' duality of structure it would be helpful to undertake observation and the examination of documentation to identify how domination and legitimation occurs through the use of power and sanctions.

\section{Data Collection and Analysis}

Interviews were conducted in 1999-2000 with thirty-two (32) female and two (2) male IT professionals working in Australia. The interviewees represent a range of ages, employment sectors, educational backgrounds and ethnic backgrounds. The males were interviewed primarily to provide insight into the female experience. Working in technical areas, the interviewees are referenced to explore the duality of the IT industry, as it is perceived by women working in the industry. The importance of operating within a male domain, including the extent of outside-work socializing with male colleagues (such as attendance at sporting events) as necessary for career progression has been identified previously (von Hellens, Nielsen and Trauth, 2001). The implication is that while women have been socialized away from IT, the IT field has been constructed as a masculine domain. This follow-up study by the collaborating authors in 2000 (Trauth et al., 2000) enabled a deeper exploration of the current position of Australian women working in technical positions in the IT industry.

This paper revisits the interview data discussed in the Trauth et al. paper (2000) and in the von Hellens et al papers $(2000 ; 2001)$ from the perspective of structure and agency. It aims to explore perceptions of the IT industry through the eyes of female IT professionals. The data collection was a collaborative effort between von Hellens and Nielsen, Australian-based researchers, and Trauth, a US-based researcher.

Semi-structured open-ended interviews of approximately 90 minutes in duration allowed interviewees to express their personal views and discuss their individual experiences in the Australian IT industry. Four main areas were covered, including demographic information, personal history, general questions about gender and IT, and recommendations regarding how society, the IT profession and educational institu- 
tions might address the gender imbalance in IT (von Hellens et al., 2001). The interviewed women are not a random sample, they were gathered primarily from the 'Women in Information Technology' (WIT) whose has a mission to sustain an active network of women in the IT industry, facilitating career development and promoting enhanced industry management in Brisbane, Australia (WIT, 2002). These women are both the subjects of our study and informed observers of the skills issues faced by women in the industry. As mentioned above, this study does not consider the observed skills required by women in the industry such as Todd et al., (1995), instead it explores the perceived perceptions of these women.

The respondents were IT practitioners working in a range of levels at a range of industries in various parts of Australia and academics in IT faculties. The respondents drew upon their own experiences to offer insights about the themes, which were explored in this study. The female subjects offered two perspectives on the topic; their experiences of entering and progressing in the IT field, and helping other women enter and succeed in IT (von Hellens et al., 2001).

The third author carried out the initial sorting and analysis of the interview data with the aid of NUD*IST, an Australian qualitative software application. NUD*IST is an acronym for Non-numerical Unstructured Data, Indexing, Searching and Theorising and is designed to aid users in handling Nonnumerical and Unstructured Data in qualitative analysis, by "supporting processes of coding data in an Index system, Searching text or searching patterns of coding and Theorising about the data" (QSR, 1997). The advantages and limitations of using this software are discussed in Beekhuyzen, Nielsen and von Hellens (2003).

An examination of our interview data using concepts from structuration theory shows that a number of dualisms provide the interviewees with interpretive schemes through which they can interpret and make sense of their working lives. Such dualisms may provide ontological security as representations of the routines which women in the IT industry enact in their daily activities. The interviews of professional women reveal contradictions in these dualisms, indicating that these polarised views of women and IT work are being undermined by women in the IT industry.

\section{Duality or Dualisms}

Central to structuration theory is the notion of duality (Giddens, 1984). In keeping with modern trends in sociology, Giddens rejected the notion of outright dualism, in which the fundamental forms of things are viewed as of two contrasting irreducible types (for example nature and nurture). According to many writers on Giddens' the notion of duality attempts to resolve the 'agency/structure debate' (Walsham and Han, 1990). This debate concerns the paradox of social reality whereby "the properties of the elements of social phenomena obtain many of their characteristics from the larger phenomena of which they are a part, while the larger entities obtain their characteristics mostly from the relations between the parts of which they are composed" (Cohen, 1968).

"Structuration is an approach to understanding the social world that replaces the dualisms of social theory with a duality of reciprocal interdependencies" (Boland, 1996). Giddens criticised contemporary sociology for treating the relationship between the individual and society as a dualism, in which individual and society are separable, and for producing social theories which focus on one side of the paradox; functionalism for example regarding the individual as produced and determined by society, whereas interpretivism regards the individual as the producer of social reality. In contrast to dualism the notion of duality proposes a dialectical interaction between conceptual pairs with no claim that that these concepts are ultimately irreducible. Thus Giddens' approach is to propose a duality of structure in which "the structural properties of social systems are both the medium and the outcome of the practices that constitute these systems" (Giddens, 1979). 
Von Hellens, Nielsen, \& Beekhuyzen

The authors identified a number of dualisms in the way women typically represent their work experiences in the IT industry (summarised in Tables 1 \& 2). This paper briefly explores some of these dualisms and how contradictions in their expression seem to indicate that polarised views of women in IT are being modified. In other words the dualisms are viewed as social structures which influence individual actions both in an enabling and constraining manner, but which over time may be reinforced, modified and transformed by individual actors. Further work on the interview data will examine the nature of reflexivity in the women's discourse, that is "the use of information about the conditions of activity as a means of regularly ordering and redefining what that activity is" (Giddens, 1984, p86). This reflexivity occurs as the women interviewed ponder the significance of the questions and their own answers.

\begin{tabular}{|c|}
\hline Dualisms of skills and attributes \\
\hline Home/work \\
\hline IT industry/career certainty \\
\hline IT work/emotion \\
\hline Intuition/analysis \\
\hline Programmer/people focused \\
\hline Soft skills/technical education \\
\hline Solving problems/talking to people \\
\hline Technology/business problems \\
\hline Technical/management \\
\hline Technical/people skills \\
\hline Technology/communication skills \\
\hline
\end{tabular}

Table 1 Dualisms in IT work

Writers in women's studies have shown how such dualisms are constructed (Barrett, 1992) depending on prevailing social tendencies (such as the dualism between individual and society as a product of the Enlightenment). They have also shown how the notion of dualism enables the promotion of one type of experience over the other so that dualisms often consist of unequal conceptual pairs, (such as active/passive, public/private) associated with gender and power (Porter, 1991).

A dualistic approach to the problem of female participation in IT can be seen in much of the literature, particularly that proposing the idea of inherent differences (e.g. Venkatesh, Morris and Ackerman, (2000) which identifies gender differences in adoption and usage of technology).

The dualisms in Table 1 represent IT work and skills as a set of either/or propositions. To be good at programming infers lack of communication skills. Technological knowledge is distinct from business knowledge. To be a woman means having good communication skills but lesser technical skills. Private or home concerns are separable from work.

\begin{tabular}{|l|l|l|}
\hline \multicolumn{1}{|c|}{ Issue } & \multicolumn{1}{c|}{ Men } & \multicolumn{1}{c|}{ Women } \\
\hline Attention to detail & Uncommon & Common \\
\hline Broad perspective & Uncommon & Common \\
\hline Continuous learning and rapid change & Common & Uncommon \\
\hline Assertiveness & Common & Uncommon \\
\hline Communication & Uncommon & Common \\
\hline Noisy vocalism & Common & Uncommon \\
\hline Political skills & Common & Uncommon \\
\hline Networking & Common & Uncommon \\
\hline Left brain & Common & Uncommon \\
\hline Programming & Common & Uncommon \\
\hline Technical skills & Common & Uncommon \\
\hline
\end{tabular}

Table 2 Gender Specific Dualisms in IT work

The dualisms in Table 2 represent skilled IT work and gender as a set of either/or propositions. To be assertive, to have political and networking skills and to be interested in continuous learning and rapid change infers masculinity. Having a broad perspective and attention to detail are viewed as being feminine traits. 


\section{Dualisms of IT Work}

A number of dualisms of IT work have been identified and these have been grouped as: Hard versus Soft Skills, Home versus Work, the Division of Labour, Routinisation, and Interpretive Schemes (Nielsen et al. 2003).

Hard versus Soft Skills: One of the most interesting dualisms is the separation of soft and hard skills, not only in terms of their association with women and men, but also in terms of how they are learned and valued. This is expressed by one interviewee as follows; 'Skills like communication and organisational .. they're things that you can train into yourself from a little child - your parents can help you with those. But things like technical skills like IT would need ... you will only get that at a tertiary institution.'

The Dualism of Home and Work: Another frequently occurring dualism is that of home/work and private/public life. This dualism is reinforced by women's choices to delay or not have children and their need to accommodate their working lives to their private responsibilities and vice versa. This is obviously not unique to the IT industry but the women interviewed perceive that it presents different problems where the majority of the work force is male and is not presented with this conflict. The workload associated with the need to keep up with the rapid rate of change is seen as difficult to reconcile with family responsibilities and makes women apprehensive about taking even short breaks from their careers, for example for maternity leave.

Dualisms and the Division of Labour: Despite the recent work on new IT enabled organisational forms, the interviews of professional women confirmed that without exception they perceive their workplaces and career paths in the IT industry in terms of traditional work specialisations. The dualisms referred to above reflect a traditional division of labour into hierarchies of skills, associated with gender, power and authority. These hierarchies are reinforced through award systems and management evaluation criteria, which purport (claim) to be objective and equitable but which "reflect entrenched managerial values" (Acker, 1990, p149). Responsibility and complexity are defined according to existing social practices; hence the undervaluing of many femininised occupations such as nursing and child care which take responsibility for human lives but which are assumed not to require the same level of training as a profession requiring more 'hard' skills such as medicine.

The gendering of IT work in this regard seems to have three consequences, as revealed in the interviews. It requires both men and women to 'adapt' to a masculinised domain, and it discourages many women and men from choosing IT as a field of study or career. Both the men and women interviewed indicated that they found the working arrangements and valuing of specific skill sets in the IT industry difficult.

Routinisation: The dualisms listed in Table 1 are expressed in the interviews in a taken for granted way. In structuration theory the habitual, taken for granted nature of everyday activities is called routinisation; according to Giddens the " the predominant form of day-to-day social activity ... In the enactment of routines agents sustain a sense of ontological security" (1984, p282). Moreover, routine is "integral to the continuity of the personality of the agent ... and to the institutions of society" (Giddens, 1984, p60).

The unselfconscious reference to and representation of traditional dualisms allows women to operate without continual self-consciousness or anomie about the nature of the work. Anomie (Lehmann, 1994) may exist where there is a conflict between personal goals and the availability of structures to support those goals, or where there is uncertainty about organisational values. In an area such as IT which is rapidly changing and which presents its professional workforce with continual challenges (including the recent dotcom crashes) the need for the ontological security provided by routinisation would be particularly strong.

Dualisms as Interpretive Schemes: The dualisms expressed above may be viewed within structuration theory as the interpretive schemes through which signification is achieved. Interpretive schemes are 
"the stocks of knowledge that human actors draw upon in order to make sense of their own and others' actions" (Walsham and Han, 1990, p54). Giddens' concept of interpretive schemes is useful in showing how these women deal with the contradictions in the way they conduct their daily working lives, "making that conduct appear rational, understandable and accountable to self and other" (Boland, 1996, p693).

The emergence of contradictions points to the possible transformation of structures of signification. In structuration theory interpretive schemes are not immutable or monolithic. The meaning of particular expressions such as 'communication' needs to be interpreted within the social context (Giddens, 1979). For example, many of the women interviewed identified networking skills as an instinctive skill at which men excel and which provides them with an advantage. Male networking is carried out not only formally but also informally through common/social interests such as sports, after work drinks sessions and so on, whereas women were more likely to go home after work and take on household and family duties. However, more recently women are developing networks through formal purposeful activities such as women in IT associations. One interviewee saw this as a means for enabling women to utilise their natural assets. 'It's all sharing and giving and more so than with guys'.

\section{Issues of Female Participation in IT}

Structuration theory illuminates two problems in studying the IT industry and workforce. Firstly, to understand the production and reproduction of social structure requires a longitudinal study but the rapid rate of change in the industry including high staff turnover make this difficult. Without a longitudinal study it is difficult to identify how individual agents reinforce, modify or transform institutionalised traditions within the IT industry.

Secondly the rapid rate of change makes it difficult to conceptualise in a meaningful way what constitutes the IT industry. Definitions produced by industry organisations (such as the Australian Bureau of Statistics) do not necessarily reflect the experience of people working in the industry. Furthermore, staff in the IT industry differ from other complex, highly paid occupations. Although the IT industry generally hires a significant number of university graduates, it lacks institutionalised forms such as required professional education, membership of associations, defined career paths and professional sanctions, which are characteristic of other complex occupations such as law, medicine, accountancy, architecture and engineering (Encel, 1970).

This lack of clarity hampers any investigation into the continuing problem of why women are not attracted to IT work. The women interviewed were themselves from a diverse set of backgrounds, with different educational qualifications and work histories. They proposed aptitudes and skills rather than specific professional education as important for success in the industry. They see the IT industry as diverse, offering many different options for work and careers.

The significance of individual women as agents in structuration, reinforcing, modifying and transforming the social structures, is therefore difficult to identify. Their discourse reveals that they perceive themselves as individuals who have overcome barriers and succeeded in the industry. They also talk about themselves as different from other women they know, indicating that they are challenging the dualism of gender. They consider that they possess the 'key skills going into the next millennium $\left[21^{\text {st }}\right.$ century]'.

\section{Mentoring}

Our current research suggests that mentoring, interactions with professional IT organisations, and professional IT women talking to females in their IT education years can give new ideas to the perceptions of IT and thus challenge these dualisms. The perceptions of the interviewees need to be altered in order 
to successfully challenge these dualisms. Exposing females involved in IT education to these professional IT women and professional organisations such at Women in IT (WIT) who are challenging these dualisms is an essential part of transforming these structures of signification.

Existing research on mentoring has focused mainly on mentoring programs within the workplace. The success of such programs depends on the level of support shown by the management of the organisation in which the program is being implemented. According to this research mentoring schemes can help companies improve the gender balance of their staff and to develop a stable corporate culture (Limerick et al., 1994).

However, there is no clear Australian evidence connecting mentoring to improvements in recruitment of students to specific areas of study. Mentoring programs in schools are aimed at achieving the fullest potential of each student in emotional health, academic achievement, interpersonal relationships and vocational knowledge through a positive relationship with at least one adult (MacCallum and Beltman, 1999). Although there is a diverse range of models of mentoring programs operating in Australian schools, there are no examples of students being mentored specifically on IT career choices.

\section{IT Mentoring Project}

An IT mentoring project was conducted in 2001 as part of the ongoing WinIT research project. The mentoring research aimed to investigate whether mentoring programs have the potential to influence and change students' perceptions and decision-making regarding IT career choices and education. The mentoring project introduced high school students to the variety of career options in the IT industry by providing successful IT professionals as role models to offer realistic advice on the nature of IT education and work. The research assumes that a mentoring program may play an important role in addressing the IT skills shortage, increasing participation in IT education by providing opportunities for informed decisions and making IT education and work more appealing to students.

The WinIT team collaborated with Information and Processing Technology (IPT) teachers at a local secondary school (MacGregor High) to establish a mentoring program for 110 Year 11 IPT students. A total of 28 mentors were sourced by the investigating team and consisted of IT professionals, academics and recent IT graduates. The role of the mentors was to assist small groups of students with the analysis and design stages of a programming assignment, as well as provide general advice about the nature of IT work, the skills needed to succeed and the wide range of options available in the industry.

The mentoring program ran for the first half of 2001 and the overall view was very positive. Most me ntors believed it was a worthwhile initiative and would be willing to support the program in the future. Students were eager to meet their mentors face-to-face and used the time to find out more about IT study and where it can lead, which helped fit the IPT subject into the bigger picture and give it a reallife context. The mentors were able to help the students with problem solving, teamwork and working the class assignment by sharing their expert knowledge on IT project principles, risk management and business systems.

One mentor highlighted the fact that the mentoring program was a good opportunity for female students to gain some insight into IT as a career, as the small number of females that are in the IT industry limits the opportunities for female students to. Identify role models. The mentoring program can therefore provide more accessible role models for female students, providing a strong positive image to female students and correcting the widely held view that IT industry is intrinsically a male domain.

As this was a pilot program, several problems were encountered. The main one was the lack of opportunity for students and mentors to meet before the program started. This would have provided a means of breaking the ice and perhaps facilitated communication and interaction during the program. Some groups made little or no effort to contact their mentors, while on the other hand, some mentors did not 
respond to student emails. There were also problems associated with differing levels of expectation between students, teachers and mentors, and a lack of specific tasks within the assignment description to assist students to make full use of their mentor resource.

Surveys and interviews with students have been conducted to determine whether the mentoring program has been successful in influencing students' perceptions of IT education and work. Feedback will also be sought from teachers and mentors. Many valuable lessons have been learnt from this study that can be used to produce guidelines for the establishment of future IT mentoring programs. The investigators aim to continue the program at MacGregor High School and expand it to include other high schools in the Griffith University catchment area.

\section{Discussion}

An important aspect of the mentoring project was its relevance to the gender issue. Although IT education is less attractive to students in general, females tend to be noticeably under-represented. This is due in part to the social construction of the IT as a male domain, whereas occupations such as teaching and nursing are considered more suitable for females. A mentoring program may provide female role models to dispel negative stereotypes and highlight the positive aspects of being a woman working in the IT field.

Statistics on student applications to university and technical education level IT courses indicate that IT education is unattractive to the majority of high achieving students in general and female students in particular. Prior research into high school and university students' perceptions of IT studies and work indicate not only considerable uncertainty about what the IT work consists of and what skills are needed to succeed as an IT professional, but also that IT work is perceived as difficult, boring and solitary in nature, requiring little interaction with fellow workers or customers (Greenhill, von Hellens, Nielsen and Pringle, 1997; Nielsen et al., 1999). As a result, female high school students lack interest in IT degree studies and the number of female IT graduates continues to be low, varying between $14 \%-20 \%$ of all students enrolled in IT degree courses.

The IT industry figures are equally unsatisfactory. According to Korn/Ferry International, only one in ten board seats is occupied by a woman (Burke, 2000). The situation on Australian go vernment boards is better $(30.9 \%)$ but still below the target figures (OSW, 2000). Some companies have put initiatives in place to rectify the situation, e.g. IBM, where women made up $18 \%$ of their executive positions globally in 1999, whereas the figure was $10.5 \%$ in 1995, when they formed a Women's Diversity Task Force (Bensten, 2000).

This paper suggests that IT mentoring could be a viable way to challenge the perceptions that females in IT education have, and to make it a more attractive career option. Conducting observations and an examination of the documentation is recommended to enable an insight into how domination and legitimation occurs through the use of power and sanctions.

\section{Conclusion}

As with all social science research, this study involves what Giddens refers to as 'the double hermene utic' (Giddens, 1982, p11-13). Subjects can take up and reject or reaffirm the research on Women in IT. In this way research projects themselves may help to bring about change as more interviewees consider the implications of the questions they are asked. This is related to the idea of reflexivity and the role of the meta level observer which is discussed in Trauth et al. (2000).

A limitation of the research so far is that it has relied on intervie ws and surveys with no data drawn from observation. Overall, the participation of women in IT remains low and this is a matter of concern, al- 
though there have been many success stories in attracting women into IT education. This paper indicates that the way women talk about their work reinforces widely held impressions of the IT industry and the use of structuration theory helps to show how this talk is not always consistent with the women's lived experiences. Mentoring is suggested in this paper as a way to challenge these dualism and structures of signification. Through mentoring, interactions between professional IT organisations, professional IT women and females in IT education can help to challenge these dualisms and therefore alter perceptions. We are currently examining the role of mentoring in the construction of female identity in the IT workforce.

In order to understand better how women help configure the institutional realm of IT work, we propose that more qualitative studies of women at work in IT as well as women talking about IT are needed. It is suggested that a 'proper' application of structuration theory would require a longitudinal study. Due to the dynamic nature of the IT industry (unlike other, more traditional industries), a longitudinalstudy could give great insight into perceptions of women in IT over time.

\section{Acknowledgements}

The authors gratefully acknowledge financial support from the Australian Research Council Large Grants scheme which funded the collection of the interview data by the first two authors and Professor Eileen Trauth. The authors are also grateful to Professor Trauth for her collaboration with the WinIT project and for allowing access to her interview data.

\section{References}

Acker, J. (1990). Hierarchies, jobs, bodies: a theory of gendered organisations. Gender and Society 4(2): 139-158.

Ahuja, M.K. (2002). Women in the information technology profession: a literature review, synthesis and research agenda. European Journal of Information Systems 11: 20-23.

Anthias, F. (1999). Theorising identity, difference and social divisions. Theorising modernity: reflexivity, environ ment and identity. In Giddens Social Theory. M. O. B. e. al. London, Longman.

Barrett, M. (1992). Words and things: materialism and method in contemporary feminist analysis. Destabislising theory: contemporary feminist debates. M. A. Barrett and A. Phillips. Cambridge, Polity Press.

Beekhuyzen, J.P., Nielsen, S.N. and von Hellens, L. (2003). Challenging the Dualisms in Female Perceptions of IT Work. Proceedings of AusWIT03; Conference on Australian Women in IT - Awarded 'Best Paper', Hobart, Tasmania, (also to be published in the Australian Journal of Information Systems).

Bensten, C. (2000). Why women hate IT: Cover Story, CIO Magazine.

Boland, R.J. (1996). Why shared meanings have no place in structuration theory: a reply to Scapens and Macintosh. Accounting, Organizations and Society 21(7/8): 691-697.

Burke, F. (2000). Women are coming on board but very slowly. The Australian: 18.

Cohen, P. (1968). Modern social theory. London, Heinemann.

Council_of_Economic_Advisors (2000). Opportunities and Gender Pay Equity in new Economic Occupations. Washington.

Encel, S. (1970). Equality and authority. London, Tavistock.

Giddens, A. (1979). Central problems in social theory. Berkeley, University of California Press.

Giddens, A. (1982). Profiles and critiques in social theory. London, Macmillan.

Giddens, A. (1984). The consitution of society. Cambridge, Polity.

Greenhill, A., von Hellens, L., Nielsen, S.H. and Pringle, R. (1997). Australian women in IT education: Meanings and multiculturalism 6th International IFIP conference on Women, Work and Computerization (WWC-97), Bonn, Germany.

Halford, S. and Leonard, P. (2001)._Gender, power and organisations. London, Palgrave. 
Jones, M.R. (1999). Structuration theory. Rethinking management information systems. W. J. Currie and R. Ga lliers. Oxford, Oxford University Press: 103-135.

Lehmann, J.M. (1994). Durkheim and women. Lincoln, Nebraska University Press.

MacCallum J. and Beltman, S. (1999). International year of older person mentoring research project, Murdoch University.

Maitland, A. (2001). A long-term solution to the IT skills shortage. Financial Times: 9.

Nielsen, S.H., von Hellens, L., Beekhuyzen, J.P. and Trauth, E. (2003). Women talking about IT work: Duality or dualism? Proceedings of the ACM SIGCPR/SIGMIS, Philadelphia, Pennsylvania.

Nielsen, S.H., von Hellens, L., Pringle, R. and Greenhill, A. (1999). Students' perceptions of Information Technology careers: Conceptualising the influence of cultural and gender factors for IT education. GATES 5(1): 30-38.

Nielsen, S.N., von Hellens, L. and Beekhuyzen, J.P. (forthcoming). Identity and difference; women working in the IT industry.

OSW (2000). Commonwealth office of the status of women (OSW). Resources: Australian women..

Porter, E. (1991). Women and moral identity. Sydney, Allen and Unwin.

Pringle, R., Nielsen, S.H., von Hellens, L., Greenhill, A. and Parfitt, L. (2000). Net Gains: Successful strategies for Pro fessional Women in IT. 7th International Conference on Women, Work and Computerization. Charting the Course to the Future IFIP TC9 WG 9.1, Columbia, Canada.

QSR (1997). QSR NUD*IST 4: User Guide. Melbourne, Sage Publications.

Todd, P.A., McKeen, J.D. and Galllupe, R.B. (1995). The evolution of IS job skills: A content analysis of IS job. MIS Quarterly 19(1): 1.

Trauth, E., Nielsen, S.H. and von Hellens, L. (2000). Explaining the IT gender gap: Australian stories. 10th Australasian Conference on Information Systems, Brisbane, Australia.

Venkatesh, V., Morris, M.G. and Ackerman, P.L. (2000). A Longitudinal field investigation of gender differences in individual technology adoption in decision-making processes. Organizational Behavior and Human Decision Processes (83): 33-60.

von Hellens, L.A., Nielsen, S.A. and Trauth, E. (2001). Breaking and Entering the Male Domain: Women in the IT Industry. ACM SIGCPR Conference, San Diego.

von Hellens, L.A. and Nielsen, S.N. (2001). Australian women in IT. Communications of the ACM 44(7): 46-52.

von Hellens, L.A., Pringle, R., Nielsen, S.H. and Greenhill, A. (2000). People, business and IT skills: the Perspective of Women in the IT industry. ACM SIGCPR, Chicago, USA.

Walsham, G. (2002). Cross-cultural software production and use: a structural analysis. MIS Quarterly 26(4): 359-380.

Walsham, G. and Han, C.K. (1990). Structuration theory and information systems research. International Conference on Information Systems.

WIT (2002). Women in Information Technology - WIT Home Page/Mission..

\section{Biographies}

Liisa von Hellens is Associate Professor and the current Head of School of Computing and Information Technology in Griffith University. She has over thirty years experience in the IT industry (including working as a programmer and systems developer) as well as university level education experience in Australia and Europe (Finland and UK). Her doctorate at Templeton College, Oxford University, was about packaged software provision and use, and her subsequent research, publications and consulting activities have covered information systems development and use in organisations, strategic quality management of software development, the management of IT human resources and the associated skills supply. Several refereed articles have been published on these topics. Since 1995 Liisa has also carried out research with Sue Nielsen (Griffith University) into the influence of culture and gender on perceptions of IT education and work, and the factors affecting female participation in IT education and work funded by the Australian Research Council. This research was referred to as "exemplary" by Niederman 
and Moore (Proceedings of the ACM SIGCPR 2000: 67-76). She is also involved in establishing an IT Mentoring Program for selected high schools in Brisbane, a project is funded by Griffith University's Strategic Improvement Grant.

Sue Nielsen has taught and worked in Information Management and Information Systems for almost twenty five years and is currently a senior lecturer in the School of Computing and IT at Griffith University. As well as her involvement with Liisa von Hellens in the WinIT and mentoring projects, she has carried out research on organisational culture and employee commitment in information systems development and software quality management. Her $\mathrm{PhD}$ from Griffith University used ethnographic methods and discourse analysis to study change management in an information technology centre. Her current research is investigating cultural differences in perceptions of time and change in information systems development and use.

Jenine Beekhuyzen is a currently a lecturer in IT Communication, an assessor for the degree's yearlong IT project and is also a Senior Research Assistant in the School of Computing and Information Technology at Griffith University. On completing her IT Honours degree on Enterprise Resource Planning Systems and Organisational Culture in 2001, she continues to be involved in a number of research projects including the WinIT project and a Cooperative Research Council (CRC) project on Smart Internet Technology. As well as being a mentor in the IT Mentoring project run by Liisa von Hellens and Sue Nielsen in Brisbane, she has also been involved in the development and commencement of a Computing and IT Alumni Mentoring program within the University that has been very successful to date. In addition to her role at Griffith University, she works as an IT consultant for a small IT organisation, ThoughtWare. Jenine has recently had a number of publications across the areas of her current work. 